\title{
Focusing on Potential: Refugee and Migrant Children as Active Learners. A Case Study in Greece
}

\author{
Margarita Mansola \\ Educational Consultant
}

\begin{abstract}
The example presented here is based on work done in Refugge Accommodation Centers in Greece, where $N G O s$ responded to the need of children for normality and schooling, aiming also to act as a bridge for chidlren's later accommodation in Greek mainstream schools. The specific case discussed here was an english speaking interdisciplinary education programme addressing children from 6-18 year olds. Results indicated the need to adopt teaching and learning approaches that are reflective and place the child right at the center of care. In this sense childrens needs are prioritised and taken care of, while usual practices ask the students to adipt to the existing educational realities fialing to acknowlege their specific needs and provide support. It also showed that in such an environment where turst is a given and well felt by all students, children do what they are menat to be: Learners.
\end{abstract}

\section{Introduction}

As societies become increasingly multicultural and complex and while national systems try to find ways to adjust to the changes of the new century, educators are called in real life and real classes to deal with this increasing complexity and the challenges this new era brings with it. Moreover, in a number of cases they are called to respond to this, without support or substantial professional development that would give them the tools to both deal with the challenges more efficiently and perhaps more importantly, empower them as teachers. One of the most salient changes that Greece faced in the past two years has been concerned with the large influx of refugee and migrant students that entered the country in 2015. This posed significant challenges to the country's education system that was called to accommodate a large and unprecedented diverse student population. More precisely, children who were uprooted from home, often without formal schooling for a long time due to violence and conflict, followed their families in long dangerous journeys and finally, found themselves in an unforeseen transition period, which only added to their predicament.
Moreover, in the event of relocation they were to face a new reality, a new language and a new education programme while still trying to overcome effects linked to disrupted or absent schooling and traumatic experiences. At the same time other variables like parental and culture attitudes, uncertainty as to the country of final residency, prolonged frustration waiting for completion of asylum services, intervene posing further difficulties.

Since 2015 and especially after the closing down of free access to Europe through the Balkans and the implementation of the EU-Turkey agreement in March 2016, most refugees and migrants arriving in Greece were left in Greece until asylum, relocation and identification processes were completed and considered [8]. Since then, Greece has received over a million refugees and migrants with $37 \%$ of this population being children. The intensity of this influx, the big numbers and most importantly the large diversity of the population in terms of language spoken, religion, culture, socio economic situation but also goals, posed a number of challenges to the Greek state. With reference to education, despite the strong political will to adopt a children rights approach and offer educational opportunities to all children, the lack of experience, weak school infrastructure and services in the State system led to delays, significant challenges and reactions [2]. Moreover, the majority of the refugee and migrant children had been out of school for months or even years due to conflict, violence and displacement. For the younger children the case often was that they had never been to school and thus were lacking basic skills while adolescents had missed out a lot of their education and development. There was also a high number of unaccompanied and separated children, the majority of whom were boys between the ages of 14 and 17 years old. As in September 2018, an estimated 25,000 children are staying in Greece, including 3,050 unaccompanied children.

The Greek state responded by offering two alternative educational routes, formal education and non-formal programs for refugee and migrant students. Formal Education: Despite the strong 
political will to accept refugee and migrant children in state schools the inadequate infrastructure, the economic crisis, the highly centralized system of education and the attitudes held in society presented a number of challenges. As a result of this, a differentiated model was designed that placed children to special classes. This was supposed to be a transitionary period that would facilitate refugee and migrant children later enrollment in state schools. Results from this plan are quite debatable even amongst educators as it has been considered to be a rather fragmented approach._More precisely, in March 2016, the Greek Ministry of Education set up "Reception/ Preparatory Classes for the "Education of Refugees" in a number of state schools (during afternoon hours) for refugee and migrant children aged 6 to 15 years who lived in refugee camps. At the same time some state schools in urban centers designed extra classes on Greek language during their morning programme and enrolled refugee and migrant children who had moved to the city. However, places were not guaranteed while social factors such as parents lacking the language and the guidance to enroll kids to school. It is estimated that, in the school year 2016/17, 2,643 children joined 145 afternoon classes in 111 public schools [2]. Refugee and migrant children and their families who moved in apartments or other premises in urban areas could be enrolled in regular morning schools. Some of these state schools organized morning "Reception Classes" for refugee and migrant children and adolescents. These classes are part of the Greek formal educational system and are addressed to pupils with limited knowledge of the Greek language. According to the Greek Ministry of Education, approximately 2,000 refugee and migrant children attended such "Morning Reception Classes" in the school year 2016/17.

Access to state schools through the refugee and migrant education program basically targeted children up to 16 year olds. For the first time, reception classes were provided for adolescents 16-18 years in Greek State High schools during the 2017-2018 academic year. It important to note, that the integration of refugee and migrant students into state schools has been implemented in a constant unstable and fluctuating environment; refugee and migrant population changed in numbers as some were transferred from the islands to the mainland and moved into different living schemes from the official refugee accommodation sites to urban apartments, hotels, as well as continue participating for family reunification and resettlement process in Greece and other European countries.

Non-Formal Education: Non-Formal Education activities ran, since the beginning of population arrivals in various parts of Greece, aiming to respond immediately to children's need for a stable psychosocial and learning environment. These programs were offered by international and local humanitarian and education organizations in the refugee camps as well as in urban community/educational centers. As time went by, they evolved targeting school readiness for children who had either not been to school at all or who had been out of school for a long time, by giving them a positive re-entrance or first-time learning experience in a classroom. Primarily, the focus was given to the social empowerment of the children, supporting their return to normalcy, integration in formal school systems and in society. In general, non-formal education programs gave the opportunity to refugee and migrant students to develop the social, cognitive and language skills they needed in order to integrate later in the host country society. These programs seemed to fit more the diverse scene of refugee and migrant children education and can help children and young people from refugee and migrant populations adjust to new educational and social realities, placing its focus on specific student populations. Still, there were a lot of issues here in terms of quality of education, monitoring of children's progress and especially funding that led to frequent disruptions and/or wrong focus and poor educational outcomes.

\section{Exploring refugee education and practices}

As stated in relevant literature and as evident to anyone who has dealt with refugee education from an educational policy level, the specific needs of refugee children and youth as a result of forced migration have been ignored. This is mostly due to the fact that most of policy making literature and practices were concerned with migration and multicultural education This has led to invisibility of the specific needs of refugee children [7]. Moreover, refugee students are usually seen as a homogenous group, failing to take into account other factors like those refereed by Rutter as "Pre migration" and "post migration" [6]. Failure to do so, leads to a common conceptualization of refugee children as "problem" rather than potential.

Another usual finding as criticized by Rutter is the overemphasis on trauma which masks the significance of other post migration experiences like prolonged encampment, poverty, isolation, uncertain migration status [6]. Such preoccupation with issues at individual level, often lead to overlook broader dimensions of disadvantage. Lastly, overemphasis on host language learning and language as a barrier often fails to acknowledge children's wider learning needs like their need to be stimulated, to inquire, to create, doubt and reflect. 
It is of little surprise then that both the State and NGO and emergency responses to refugee education in Greece were at best following practices that have been criticized and reassessed for their effectiveness and their failing to provide sustainable development structures. Although they all feel that they are doing the best they could, they have both been inadequate in providing the most for refugee children, especially in terms of meeting their needs and providing more sustainable structures than just emergency aid. While this is a complex issue to discuss, beyond the scope of this paper, case studies where a different approach was chosen will be presented as an alternative model.

\section{A Case Study adopting a different approach}

When the present project was initiated under the Non Formal Education funding from EU, there was an intended purpose to offer something different that could be closer to children's needs. To this end, needs assessment was carried out first and close continuous monitoring of students' development and learning were a priority. Students were residing in refugee camps experiencing conditions that were not always appropriate for their age. Their background in language, religion, cultural beliefs or schooling experience varied considerably which meant that there were significant challenges primarily in communication but also in their expectations as well as in the relationships between themselves as students. It was clear that a priority for the program, if it was to be successful, was to establish a sense of an organized, safe classroom environment where all students are equally valued and helped. Adopting an approach of a Resilient Classroom, designing the program was based on its most basic assumption that "effective classroom environments will increase children's availability for learning by increasing their academic engagement and enhancing their behavioural discipline" [1]. More precisely some of the characteristics of the program that shaped it were:

\subsection{Adopting a common language (English)}

English was immediately set as the language of instruction and of all communication. This placed all learners in the same position of learning a new language. Using a lot of body language and theatrical speech combined with vivid and performative narrations soon attracted children's interest and established the norm of "trying to communicate". The teacher was the point of reference as well as the leader in modeling this behavior and respecting all voices heard or difficulties. However, ample space was left for mother tongue to be celebrated as through targeted activities that brought awareness and appreciation of the wealth of other cultures and their significance.

\subsection{Building classroom ethos and respect}

Rules were formulated quite early in the project together with children and graphically presented in posters by the children themselves using symbols drawings etc. Modeling acceptable behavior and being strict and steady with the rules adopted by all, soon made it it clear that only in this way can we all cooperate effectively. This was the main message conveyed. A number of Social Emotional Leaning activities combined with language learning like for example through children or teenager literature were common practice to elicit responses from children and develop empathy.

\subsection{Choosing or developing age appropriate and stimulating educational material and curricula}

Instead of teaching English as a foreign language which is what many other camp educational programmes did, it was felt that the children had more complex cognitive and learning needs so an English non-formal educational programme that took these into consideration was developed. This included a number of interdisciplinary school subjects and development of curricula to encourage children to learn about the world around them - such as geography, biology, mathematics and social sciences.

\subsection{Adopting reflective teaching and Differentiated Instruction as a model of instruction}

Every class was diverse. As explained earlier, children came from varied environments, with different strengths, weaknesses, difficulties, problems, dreams and wishes. Some had been out of school for more than two years, or never had schooling. Many lagged behind in terms of knowledge base and learning skills. It was therefore imperative to carefully adjust teaching material and approach to meet their needs.Teaching was delivered through differentiated instruction and through building trust and confidence.

\subsection{Adopting an Intercultural Approach}

While all cultures were well accepted and celebrated and differences respected. It was well acknowledged that we can all be different but there are so many things that unite us. Carefully selected thematic units for teaching made this even more evident incorporating social emotional learning 
aspects and psychosocial extensions led not only to help children deal with individual needs for emotional safety but also created empathy and understanding addressing in this way all students and teachers in the school community.

\subsection{Adopting the CLIL methodology (Content and Language Integrated Learning) as the most suitable for a Multilanguage classroom}

In this methodology there is equal focus on advancing knowledge, skills and understanding related to the specific theme taught, using language to learn but also learn how to use language, advance thinking skills, understanding and language and get exposed to different perspectives. Listening, reading, speaking and writing are again all developed though this approach.

\subsection{Adopting a Growth Mindset}

Adoption a growth mindset, clearly conveyed in all aspects of the teaching and learning process was perhaps the most salient characteristic of the programme. Children came to believe in themselves, saw and felt their progress while self-monitoring was enhanced . Scaffolding was offered to all children and a sense of accomplishment and pride was evident. Thi soon led to positive attitudes to schooling as well as to the development of metacognitive abilities that atught students how to learn and why rather than simply what to learn.

\subsection{Focus on Social Emotional learning as an approach}

Social and emotional learning (SEL) was a critical component of the educational experience with increasing evidence showing that in order to develop healthier school climates and improved academic results, schools must teach the whole student.

SEL was not a one-off activity or simple but was incorporated in language and other learning activities. In addition to Self-Awareness (the ability to understand and manage your own feelings and to know your strengths and weaknesses) and SelfManagement (the ability to manage your behaviour and impulses, to have integrity, and to act according to your values) a SEL programme extends to increase through learning students' Social Awareness (the ability to understand and have empathy for others), Relationship Management (knowing how to work with others and get along effectively) and Responsible Decision Making (the ability to make good decisions and know how to problem solve effectively both alone and in groups.

\section{An example of teaching reading and writing in a class of 9-11-year-old residing in a refugee accommodation site}

For a couple of days, the teacher brought attractive impressively illustrated books in class for children to view and comment in groups. All children showed great enthusiasm and looked eagerly in the books. Teacher facilitated group sharing and explained key vocabulary while she introduced important professions like "paleontologist" and their work. All children were encouraged to express their impressions of the books in any way they felt comfortable with (eg. Drawing, speaking, facilitated speaking etc). At the same time children were taught important social skills like turn taking, sharing, helping each other, collaborating.

Next lesson was based a text tailor made to fit the different levels of all students, focusing on grammar and vocabulary relevant to the topic of Dinosaurs, Paleontology, etc Drills, writing and word games were all adjusted to this. To facilitate reading, echo reading was introduced followed by group reading which made everyone feel confident. Children who were more advanced, volunteered to read aloud later.

Over the following lesson the teacher brought in class a "paleontologist kit" and children had to become "explorers" and "dig" carefully to "discover" a skeleton of a T-Rex. Children were so eager to do this that they were united under this goal. They were excellent in taking turns with the "digging tools" as there were only a few of them, assigned roles (putting the bones together once "discovered,) shared the enthusiasm of "discovering" and making sure everything was back in place in a clean well tied up classroom after they finished. Following to this activity, children made a group discussion on extinct species, fossils, ice age etc and asked for more material to bring in class.

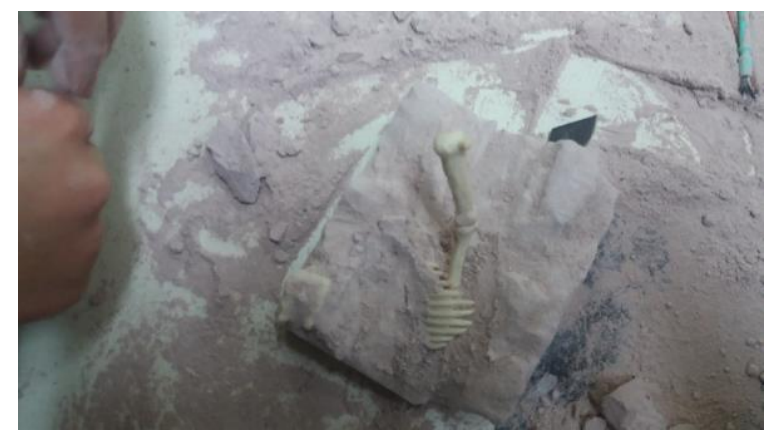

Figure 1. Digging as palaeontologists

Upon this, a lot of reading and writing practice followed with gap filling exercises, carefully designed to fit all levels in class so that all could accomplish it 
given scaffolding. At times scaffolding was encouraged between themselves, carefully monitored by the teacher. This boosted children's self-confidence and academic self-efficacy and led to more positive attitudes in school.

At the end of the Dinosaur thematic, children cooperated to "build" a museum in class were their discovery was exhibited. Children form other classes came to visit and admire their work and the group proudly "explained the work of a paleontologist" by showing their work and explaining posters and photos exhibited in class.

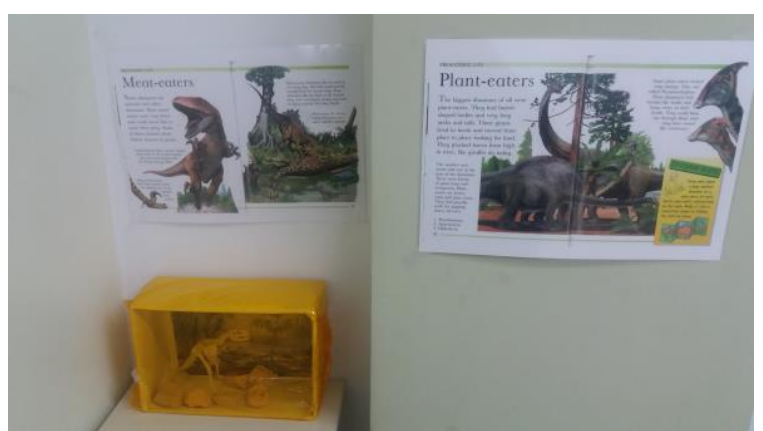

Figure 2. A Museum with our findings

\section{Conclusion}

It would not be possible to list here all activities and material that were used in the program. There have been amazing responses from teenagers who discussed resilience and developed empathy through reading about people like Hellen Keller or Beethoven, people who chose to live and create and offer rather than bend under their misfortune. Young children who felt the power of acceptance and sharing through stories and dramatization, drawings and songs. There are also tools that can be used, to be found in relevant publications, some of which actually developed in Greece though these programs. Rather, we chose a general approach that will hopefully appeal to teachers and refers to resilient classrooms and holistic teaching that can lead to meaningful learning irrespective of challenges. What we wished to stress was that we need to change the story and realize that refugee children as all children are native learners and as such, they have potential. It is our task as educators to bring learning to students and in this case all it takes is to believe in them.

\section{References}

[1] Doll, B., Zucker, S., \& Brehm, K. (2014). Resilient classrooms: Creating healthy environments for learning (2nd ed.). New York: Guilford Press.
[2] ESPN Flash Report 2017/67. Integrating refugee and migrant children into the educational system in Greece. Retrieved from file:///C:/Users/User/AppData/Local/ Packages/Microsoft.MicrosoftEdge_8wekyb3d8bbwe/ TempState/Downloads/ESPN\%20-\%20Flash\%20Report\%2 02017-67\%20-\%20EL\%20-\%20July\%202017\%20(3).pdf

[3] European Commission's Directorate-General for European Civil Protection and Humanitarian Aid Operations [ECHO] (2017). ECHO Factsheet-Greece: Response to the Refugee Crisis - July 2017. Retrieved from: https://reliefweb.int/report/ greece/echo-factsheet-greeceresponse-refugee-crisis-july-2017-enel.

[4] Pasi, R.J., (2001) Higher Expectations. Promoting Social Emotional Learning and Academic Achievement in your School, Teachers College Press, New York

[5] Pinson,H. and M.Arnot (2007) Sociology of Education and the wasteleand of refugee education research. British Journal of Sociology of Education 28(3):399-407

[6] Rutter, J., (2001) Supporting Refugee Children in $21^{\text {st }}$ century Britain: a compendium of essential information. Stoke on Trent: Trentham Books

[7] Sidhu,R. and S.Taylor (2007) Educational provision for refugee youthin Australia: left to chance? Journal of Sociology 43(3):283-300

[8] United Nations High Commissioner for Refugees. (2016, January 1-May 31). UNHCR Greece Factsheet. Retrieved May2016 